\title{
Automatic Fuel Monitoring System
}

\author{
Rajesh Krishnasamy, Ramkumar Aathi, Booma Jayapalan, K.Karthikeyen , Mohamed Nowfal,
}

\begin{abstract}
This proposed methodology is derived for automatic fuel level measurement by smart device. The discovery of automobile vehicles is a blessing to human beings from engineering and science. The majority of the transport fuels are powered by traditional fuels like gasoline, octane, diesel etc. The price of these transport fuels are also increasing. The objective of this project is to describe the automatic prevention of fuel theft by the drivers and also we are going to bring solution for how accurately the petrol bunk is filling the fuel for your vehicles. The advantage of our project is we also done with fuel indication system. Whenever liquid level goes high or low it will indicate by an alarm signal. When the flow rate or fuel consumption rate becomes more than usual rate the fuel level falls drastically then the sensor is activated and sends a signal. After receiving the signal the GSM module sends a message to a specific number by indicating something unusual. It is also been found that it is low cost technology and it can also be implemented in all the vehicles.
\end{abstract}

Keywords : Microcontroller, Float sensor, Fuel tank, GSM module, Theft detector, Alert system, IC 741

\section{INTRODUCTION}

Automatic is required to deal with all kind of frameworks. It is made conceivable by installed structure which is a blend of both PC and mechanical framework, frequently with the ongoing processing requirements. In this day and age, usually to control the large portion of the gadgets via robotization since it improves by diminishing the size and cost of the item and increment the dependability and execution. Implanted frameworks depend on micr

o controllers and their applications run from compact gadgets to huge complex frameworks. Specific interior interchanges

Revised Manuscript Received on December 05, 2019.

Dr.Rajesh Krishnasamy, EEE, Kalasalingam Academy of Research and Education, Anand Nagar, Krishnankoil, Virudhunagar, India, rajeshkrishme1987@gmail.com,

Dr.Ramkumar Aathi, EEE, Kalasalingam Academy of Research and Education, Anand Nagar, Krishnannkoil, Virudhunagar, India a.ramkumar@klu.ac.in

Dr.Booma Jayapalan, Assis.Prof, EEE, PSNA College of Engineering, Dindugal, India, boomadhyana2009@gmail.com

Mr.K.Karthikeyen, UG Student, EEE, Kalasalingam Academy of Research and

Education

Anand Nagar, Krishnannkoil, Virudhunagar, India karthi131995@gmail.com

Mr. Mohamed Nowfal, UG Student, EEE, Kalasalingam Academy of Research and Education. Anand Nagar, Krishnannkoil, Virudhunagar, India mohamadnowfalm@gmail.com organize which requires for vehicle control, for example, affirmation of message conveyance of non-clashing messages. It is normal to transportation framework that has been influenced by numerous causes, for example, fuel burglary, untimely dry out, fuel spillage, and ill-advised fuel utilization in motor and debate amid the fuelling of vehicle.

These issues cause a radical misfortune in fuel level, which thus makes the experts to get into an extraordinary inconvenience. It prompts an unreasonable effect to the specialists since fuel burglary is a noteworthy issue looked by the proprietors and drivers. It is a nearby mistake that happens in the vehicle transported, in light of the fact that fuel robbery offers the unapproved people in a recipient part. Since it prompts gigantic misfortune for the speculators and yet, it clears a path for the general population who include in unlawful exercises. The proposed framework analyzes to identify the measure of fuel burglary in all perspectives and lingerie the experts with the forthcoming procedures will in general lessen the fuel robbery in a viable way which is the shelter to our general public. This surprising fuel misfortune greatly affects the economy of a nation. It is disturbing and bothersome issue for creating nations like Bangladesh, India and China and so on. Oil and diesel robbery is a global issue. In the creating nations the fuel burglary rate is extraordinarily high. Along these lines, the issue of fuel burglary has turned into a noteworthy inconvenience for the clients which may one of the causes to determine expanding fuel cost. For example, since 2003 fuel costs has been multiplied in Canada and yearly tripled in USA, to recognize the fuel robbery issue just as abruptly decline the fuel level distinctive sensors have been concocted, for example, weight sensor, capacitor sensor, 3 ultrasonic sensors, Float sensors, and so forth.

\section{COMPARATIVE ANALYSIS}

These sensors have a few points of interest and weaknesses, for example, weight sensors are reasonable for huge size of fuel tanks. It isn't reasonable for little range. In this work, drift sensor is utilized. It is extremely useful to avoid fuel burglary rate as it is exceptionall precise concerning different sensors. This paper clarifies a successful and propelled framework execution for fuel level checking and guarantees most extreme security utilizing GSM module. The proposed framework has been intended to work with GSM innovation which will make an impression on a particular number. At the point when fuel level falls definitely, GSM is developing innovation and at present there is no territory where GSM arrange isn't accessible. Versatile correspondence makes this innovation reasonable and one of a kind so that a significant number of the framework or applications planned to work with GSM. 
GSM innovation is a wide covering region, executed and following gauges. So the principle goal of this work paper is to identify anomalous fuel stream rate transport vehicle with the assistance of buoy sensor and by the essential program of Arduino, it will send a flag to GSM module then the GSM module will tell the clients by sending message of the extraordinary fuel falling. Basically this innovation is utilized for the vehicle as well as it tends to be utilized in the fuel stockpiling tank in ventures. So this can be a superior decision for mechanical application. In a word, the primary point of view of this work is to detect the anomalous fuel stream rate of transport vehicle and keep this bizarre fuel robbery. The establishment of these setup isn't tedious it has been discovered that it is an extremely cost proficient and compelling innovation and can guarantee propelled security.

Fuel Management Systems (FMS) are utilized to maintain, control and screen the fuel utilization in an association that utilizes transport, including: rail, street, air and water as methods for business. Right now the associations are confronting a difficult issue of dealing with the fuel transportation because of manual checking. This manual checking gives a wasteful method for figuring and dissecting the fuel ingestion and can prompt budgetary misfortunes for the organization. In the run of the mill situation utilized by most associations there is no logging or examining component to watch that the quantity of litters composed on the receipt relate to the real measure of fuel in the tank.

The driver takes the vehicle to the fuel warehouse, fills the tank and gets the receipt from the siphon director, referencing the quantity of litters of fuel embedded into the vehicle tank, date and the sum. The driver gives this receipt to the individual accountable for the association, which keeps up the record and sends the sum to the siphon proprietor toward the month's end.

\section{LITERATURE REVIEW}

GSM technology is a worldwide utilized, wide covering zone, actualized and following norms. So the primary goal of this work paper is to distinguish irregular fuel stream rate transport vehicle with the assistance of buoy sensor and by the fundamental program of Arduino, it will send a flag to GSM module then the GSM module will tell the users by sending message of the exceptional fuel falling. For all intents and purposes this innovation is utilized not just for the vehicle yet in addition it very well may be utilized in the fuel stockpiling tank in ventures. So this can be a superior decision for modern application. In a word, the principle point of view of this work is to detect the unusual fuel stream rate of transport vehicle and keep this surprising fuel burglary [1].

GSM offers wide scope of administrations like voice, information and internet access. The low cost mobile communication is utilized in GSM utilizing portable correspondence the users can initiate ON/OFF control remotely. A GSM modem is a particular sort of modem which acknowledges a SIM card, and works over a membership to a portable administrator, much the same as a cell phone. In this work, SIM 300cz GSM module is utilized. SIM $300 \mathrm{cz}$ is an incredible asset which can deal with frequencies EGSM $900 \mathrm{MHz}$, DCS 1800 and PCS 1900 MHz's. It is a triband GMS/GPRS gadget.
GPRS coding plans via CS-1, CS-2, CS-3 also, CS-4 [2-7]. In this work utilized AVR microcontroller AT mega 32. The framework is interfaced with the GSM modem. The GSM modem is associated with the microcontroller through a dimension shifter MAX232 and a RS232 link. The GSM modem is a quad band GSM modem for immediate and simple combination to RS232 applications [8-12].

The Arduino Uno is a microcontroller board dependent on the ATmega328. It has 20 computerized input/yield pins (of which 6 can be utilized as PWM pins and 6 can be utilized as simple information sources), a $16 \mathrm{MHz}$ resonator, a USB association, a power jack, an in-circuit framework programming (ICSP) header, and a reset catch.

The Uno contrasts from every single going before board in that it doesn't utilize the FTDI USB-toserial driver chip. Rather, it includes an ATmega16U2 customized as a USB-to-sequential converter. This assistant microcontroller has its own USB boot loader, which permits propelled clients to reinvent it [4]. The Module, interfaced can be preserved as RAM, Input/yield, extended parallel I/O.

The resultant flag, connected to the LCD's Enable (E) input, checks in the information. [13-19].

\section{COMPONENTS}

The components which are used in this proposed work are mentioned below;

1. Float sensor

2. Arduino microcontroller

3. GSM Module

4. Digital display

5. IC 741 (OP)

\section{Proposed methodology}

This proposed system may comprise of hardware part just as programming part which is shown in fig 1 . Hardware part is utilized for detecting number of litters and utilized for communication of information preparing though programming part is utilized for the representation of information.

The proposed framework chiefly comprises of 3 modules in particular inserted framework module, GSM communication module and GPS following module. This structure is like the one introduced previously.

The installed framework module gets data from the fuel vehicles, keeps up record and sends messages to the observing operators through communication module. The GPS following module is utilized for the ongoing following of fuel tankers. 


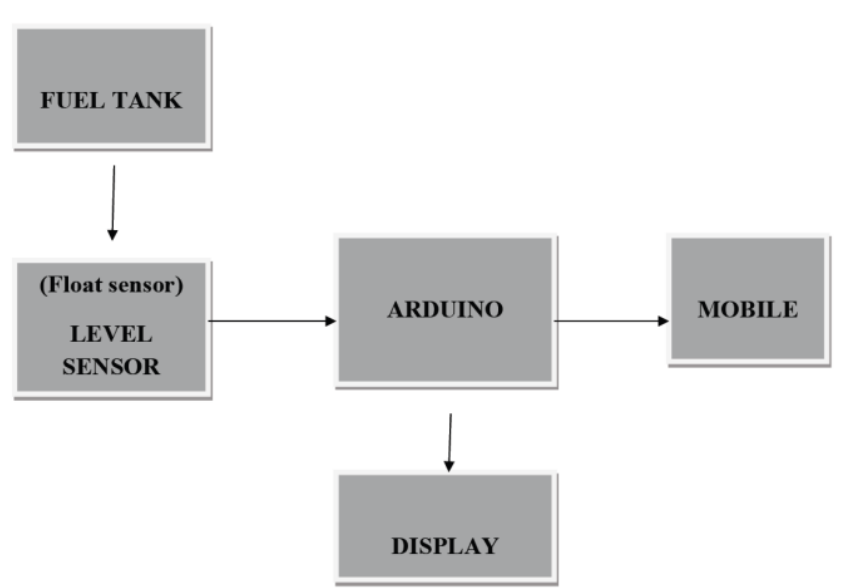

Fig 1. FLOW CHART FOR PROPOSED SYSTEM

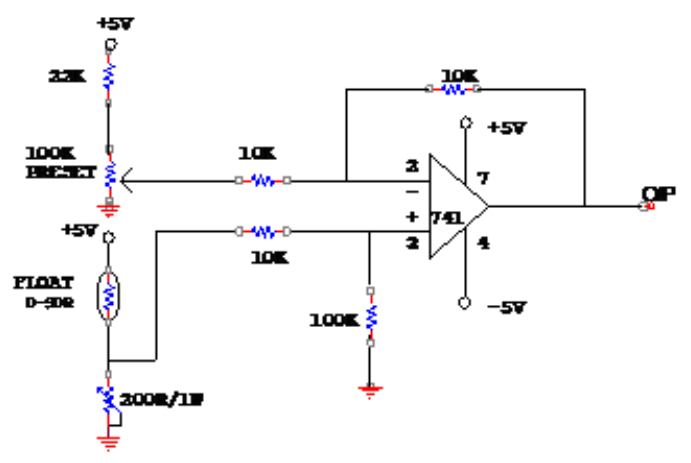

Fig 2. CIRCUIT DIAGRAM FOR PROPOSED

\section{SYSTEM}

Fig 2 describes the circuit diagram of the proposed methodology. The fuel is sensed by the float sensor.If the fuel level becomes a high level the resistance decreases. IC 741 op-amp is used to amplifier. The output from the float sensor in fed to the amplifier through potential divider circuit. The voltage output from the sensor is fed to the (op. amplifier IC 741) non-inverting input of IC. The inverting of differential amplifier is connected to a potential divider circuit by adjusting 2K2 variable resistor petrol low level correction will be made. After petrol high level calibration the difference between inverting and non inverting input is amplified.

The gain of the amplifier is " 1 " so the difference is not changed and fed to the next stage to the external microcontroller circuit

\section{A .Embedded system}

This proposed module embedded framework module is made out of fuel level sensor and a preparing unit known as Arduino Mega 2560. So as to calculate tanker volume the distance sensor HC-SR04 is utilized which works by conveying a beat of ultrasonic sound and estimating the measure of time it takes for the sound to return in the wake of hitting the fuel surface. The sensor is executed with Arduino controller to measure and handling the separation above fuel level.

\section{COMMUNICATION MODULE}

This proposed methodology fundamentally relies upon the correspondence module for sending and checking of information remotely. The deliberate information is sent remotely for further investigation.

\section{SYSTEM SOFTWARE}

This proposed methodology is plan stage and advancement condition for a visual programming language. It contains vehicle's number plate, tanker capacity, number of lost fuel litters, all out number of fuel litters conveyed in a month, absolute cost of the fuel in a month and complete misfortune/benefit in a month.

LABVIEW coordinates flawlessly with thousands of various equipment gadgets, and helps spare improvement time with advantageous highlights and a predictable programming structure over all equipment. The flowchart portrays the strategy for accepting message through GSM modem into LABVIEW condition and thus separating the information from it.

The database contains the information of all predefined fuel tankers, each having individual framework for the observing of fuel. Sound from the chime the motor will alert the outwardly hindered. In like manner, the yellow LED will swing ON to alert the person before the stick.

\section{RESULTS}

Prototype of the proposed methodology prepared is given in Fig.3. The user can get to the amount of fuel in the tank through this GSM and GPS innovation.

The keypad is opened utilizing the secret password. A signal is sent for fuel confirmation. On the off chance that fuel is past the scope of the sensor the ringer will go "on" for two minutes and all the while a instant message is sent to the proprietor.

The intruder can't stop the ringer and if the bell isn't halted inside two minutes then it will be treated as a burglary of fuel and vehicle what's more, a message is sent to the police headquarters and to beforehand put away numbers with co-ordinates of that area

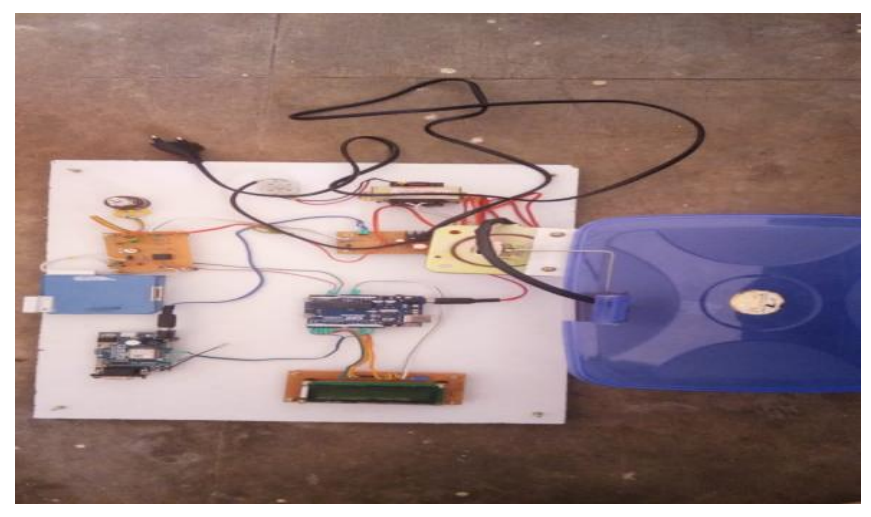

Fig 3. PROTOTYPE OF THE PROPOSED SYSTEM 


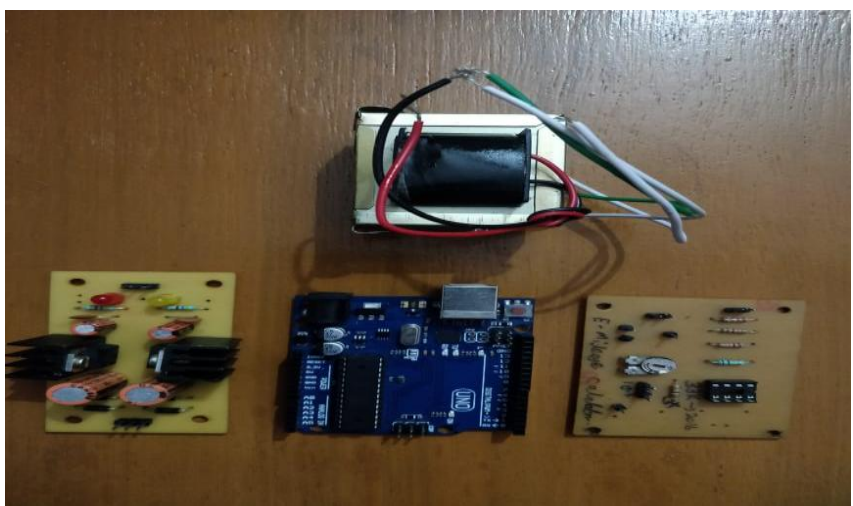

Fig 4. HARDWARE KIT

\section{CONCLUSION}

Due to rising costs of fuel the requirement for following fuel robbery is important. At whatever point there is interruption or then again altering of fuel and fuel tank the keen framework is actuated giving the proprietor the exact sign of vehicle and its fuel content. The basic reason for this work which is security that is given by the GPS and GSM module functioning. In this exploration work a development and practical methodology for fuel security has been proposed. It very well may be introduced in a little space which can't be effectively gotten too. The unmistakable element of this framework is, it ceaselessly sends the instant message to the proprietor until the proprietor recognizes consequently. Indeed despite the fact that these and numerous frameworks are being used however most of them are either costly, questionable, confused in configuration involving more space and insufficient for long separation flag transmission. Further improvement should be possible by making utilization of propelled sensors, SIM, microcontrollers to make it full verification.

\section{REFERENCES}

1. V.Hachenburg, B. D. Holm, and J. I. Smith, "Data signalling functions for a cellular mobile telephone system," Vehicular Technology, IEEE Transactions on, vol. 26, pp. 82-88, 2019.

2. Stop Diesel Theft: 6 Ways to Prevent Diesel Fuel Thieves. 2014; [cited on 19 July 2014]; Available from: <http://pro-vigil.com/2008/06/stop-diesel-theft-6-ways-to-prevent-dies elfuel- thieves/>

3. G.D.Obikoya, "Design, construction, and implementation of a remote fuel-level monitoring system," EURASIP Journal on Wireless Communications and Networking, vol. 76, pp. 1-10, 2018

4. G. Lu, H. Hue, B. He, andS. Chen, "A new-type sensor for monitoring oil-water interface level and oil level," in Electronic Measurement \& Instruments, 2009. ICEMI 09. $9^{\text {th }}$ International Conference on, 2019, pp. 981-983.

5. E. Terzic, J. Terzic, R. Nagarajah, and M. Alamgir, "Capacitive Sensing Technology," in A Neural Network Aproach to Fluid Quantity Measurement in Dynamic Environments, ed: Springer, 2017, pp. 11-37.

6. N. I. Giannoccaro and L. Spedicato, "Ultrasonic Sensors for Measurements of Liquid Level, Volume and Volumetric Flow in a Tank," Precision Instrument and Technology, vol. 1, pp. 1-6, 2017.

7. H. Huang, S. Xiao, X. Meng, and Y. Xiong, "A remote home security system based on wireless sensor network and GSM technology," in Networks Security Wireless Communications and Trusted Computing (NSWCTC), 2010 Second International Conference on, 2010, pp. 535-538.

8. G. Bucci andC. Landi, "Numerical method for transit time measurement in ultrasonic sensor applications," Instrumentation and Measurement, IEEE Transactions on, vol. 46, pp. 1241-1246, 1997.
9. S. Oh, L. Schenato, P. Chen, and S. Sastry, "Tracking and coordination of multiple agents using sensor networks: system design, algorithms and experiments," Proceedings of the IEEE, vol. 95, pp. 234-254, 2007.

10. M. A. Mazidi, J. G. Mazidi, and R. D. McKinlay, The 8051 microcontroller and embedded systems vol. 1: Prentice hall Upper Saddle River, NJ, USA: 2000.

11. Nithya and M.Hemalatha, "GSM based cost effective street lighting application," Procedia Engineering, vol. 30, pp. 737-741, 2012.

12. P. U. Ketkar, K. P. Tayade, A. P. Kulkarni, and R. M. Tugnayat, "GSM Mobile Phone Based LED Scrolling Message Display System," International Journal of Scientific Engineering and Technology, vol. 2, pp. $149-55,2013$

13. K. Foram, M. Anubbhav, and M. Pritish, "Display Message on Notice Board using GSM," Advance in Electronic and Electric Engineering, vol. 3, pp. 827-832, 2013.

14. S. R. Khan, A. Ferdousi, and S. R. Khan, "Real Time Generator Fue level Measurement Meter Embedded with Ultrasound Sensor and Data Acquisition System," Journal of Automation and Control Engineering Vol, vol. 1, 2013.

15. S. Sharieh, A. Ferworn, and VToronov, "A GSM mobile system to monitor brain function using a near-infrared light sensor," in Electrical and Computer Engineering, 2008. CCECE 2008. Canadian Conference on, 2008, pp. 000665-000668.

16. B. Nagaraja, R. Rayappa, M. Mahesh, C. M. Patil, and T. Manjunath, "Design \& Development of a GSM Based Vehicle Theft Control System," in Advanced Computer Control, 2009.ICACC'09. International Conference on, 2009, pp. 148-152.

17. V. Pandya and D.Shukla, "GSM Modem Based Data Acquisition System," International Journal of Computational Engineering Research, vol. 2, p. 1663, 2013.

18. B. Yuksekkaya, A. A. Kayalar, M. B. Tosun, M. K. Ozcan, and A. Z Alkar, "A GSM internet and speech controlled wireless interactive home automation system," Consumer Electronics, IEEE Transactions on, vol 52, pp. 837-843, 2006.

19. Y. Zhao and Z. Ye, "A low cost GSM/GPRS based wireless home security system," Consumer Electronics, IEEE Transactions on, vol. 54, pp. 567-572, 2008.

\section{AUTHORS PROFILE}

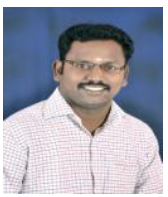

K. Rajesh was born in Rajapalayam, Tamil Nadu, India, in May 1987. He received his UG degree in Electrical Engineering from Anna University, Chennai in 2008 and M.E. degree in Power Systems Engineering from Anna University, Tirunelveli, Tamil Nadu, India, in 2011. Since July 2011, he has been working as an Assistant Professor in the Department of Electrical \& Electronics Engineering, Kalasalingam University, Krishnankoil, Virudhunagar District, Tamil Nadu and India.

$\mathrm{He}$ has attended several international conferences and he has been actively involving himself in research since 2013. Three of his research papers have been published in international journals and a research paper has been published in national journal. His current research interests include generation expansion planning, energy planning, power system optimization and power system control. He has actively participated in various faculty development programs, symposiums, orientation programs, workshops and national seminars. He has received Teaching Competency Award in the year 2015 and Research Competency Award in the year 2015 \& 2017. He is a Lifemember of ISTE and Member of IE(I).

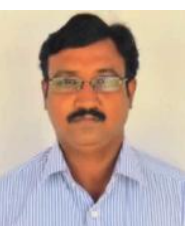

A. Ramkumar received the Ph.D degree from Kalasalingam Academy of Research andEducation in the year of 2014. He received the M.E (Power Systems) degree from Faculty of Engineering and Technology, Annamalai University, Chidambaram, Tamil Nadu, India, in2002 and received the B.E (Electrical and Electronics Engineering) from Thiagarajar Collegeof Engineering, M.K. University, Madurai, Tamil Nadu, India in the year of 1997. He hasbeen working as a Associate Professor in the Department of Electrical and ElectronicsEngineering, Kalasalingam Academy of Research and Education, Srivilliputhur, Tamil Nadu,since 2003. He is having more than 19 years' experience in the field of teaching. His researchinterests include Renewable Energy, Power System Planning, Power System Analysis, HighVoltage DC transmission Systems, Reactive Power Compensation, Flexible ACtransmissions Systems, Electrical Machines and Power System Automation. He is a Lifemember of ISTE and Member of IE(I).

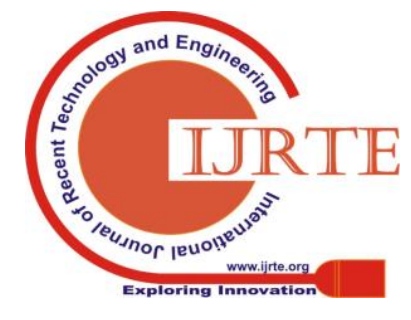




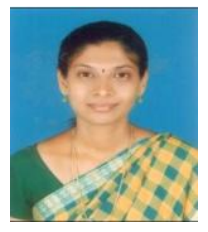

J.Booma received the B.E., Degree from Madurai Kamara University, Madurai, M.E., and Ph.D from Anna University, Chennai, She is presently working as Assistant Professor in the Department of Electrical and Electronics Engineering, PSNA College of Engineering and Technology, Dindigul, India. She has presented papers in more than 30 National and International conferences. She has published 10 papers in National and International Journals. Her field of interest includes Renewable Energy, Power system planning and Control Systems. She is a Life member of ISTE.

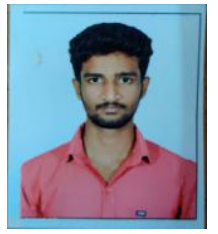

K.Karthikeyen, UG Student, persuinig B.Tech degree in the field of Electrical and Electronics Engineering, Kalasalingam Academy of Research and Education, Anand Nagar, Krishnannkoil.

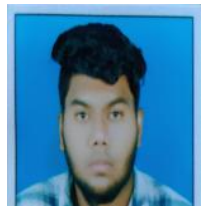

Mohamed Nowfal, UG Student, persuinig B.Tech degree in the field of Electrical and Electronics Engineering, Kalasalingam Academy of Research and Education Anand Nagar, Krishnannkoil 